\title{
El desafío de pensar. Creación - recreación
}

Débora Irina Belmes*

\section{Resumen / El desafío de pensar: creación - recreación}

El trabajo aborda la temática de la creatividad a partir del vacío teórico -y también oportunidad-generado por la pérdida de la seguridad, estabilidad y solidez que el paradigma de la modernidad otorgó para la construcción de teorías que permitieran aprehender la realidad. Analiza algunas líneas que el momento actual presenta, talescomo las nociones de tiempo y espacio que se han flexibilizado, la complejidad y la incertidumbre que se han infiltrado. Estas perspectivas posibilitan pensar cuáles son lasoportunidadesque estos nuevostiempos habilitan. ¿Qué ocurre con la constitución de saberessi el sujeto es otro? El espacio se ha tranformado. El mundo se ha globalizado pero el sujeto se encuentra cada vez más aislado. La problemática se plantea en tanto se asiste a una creación/recreación como mera repetición, reproducción en la construcción del sí mismo, o la creación y la recreación como oportunidad que la misma complejidad, desde su diferencia, posibilita.

\section{Palabras clave}

creación - desafío - incertidumbre - modernidad - paradigma - recreación - seguridad - sujeto.

\section{Summary / The challenge of thinking: creation - recreation}

The work try to broad the thematic of creativity starting from the theoretical emptiness- and also opportunity- generated due to the lost of security, stability and strengthen that the modern paradigm gave for the building of theories that would aloud to apprehend reality. Analysis some lines which nowadays have been presented as the notion of time and space which have been bent, while complexity and uncertainty have infiltrated. These perspectives we can think which opportunities are enabled these days. What happens with the construction of knowledge if the subject is another? Space has changed. The world has globalise but the individual finds itself even more isolated. The problematic raises when we assist creation/ recreation as only repetition, reproduction on the construction itself, or the creation and recreation as an opportunity of the same complexity, from its difference, allowing us.

\section{Key words}

creation - challenge - modernity - paradigm - recreation - security - subject - uncertainty.

\section{Resumo / O Desafío de Pensar: criação - recreação}

Este trabalho desenvolve a temática da creatividade desde o vazío teorico - ou também oportunidadegerado pela perda da seguridade, estabilidade e solidez que o paradigma da modernidade outorgou para a construção de teorias que permitissem apreender a realidade. Analiza algumas lineas que o momento atual apresenta, tais como as noções de tempo e espaço, que têm se flexibilizado, a complexidade e a incerteza que tem se infiltrado. Dentro deste quadro podemos refletir sob quais são aso portunidadesque estesnovostempos habilitam. O que aconteçe com a constituição de saberesse o sujeto é outro?. O espaço tem sido modificado. O mundo é agora globalizado, maiso sujeto esta cada vez maisisolado. A questão existe em tanto se assiste a uma criação/recreação como simples repetição, reprodução na construção de si mesmo. Ou criamos e recreamos como oportunidade de que a mesma complexidade (e desde sua mesma diferença) nos possibilita.

\section{Palavras chave}

criaçao - desafío - incerteza - modernidade - paradigma - recreação - seguridade - sujeito.

\footnotetext{
* Centro de Estudios en Diseño y Comunicación, Facultad de Diseño y Comunicación, Universidad de Palermo. infocedyc@palermo.edu Debora Belmes: Lic. en Sociología (UBA), Lic. en Psicología (UBA). Profesora en enseñanza normal y especial en Sociología (UBA). Profesora de la Facultad de Diseño y Comunicación de la UP
} 


\section{En el principio creó Dios (Génesis-1)}

Pensar la noción de creatividad implica desde su etimología posicionarse en un tiempo y lugar determinado, ya que nos habla de un origen, de algo que se inicia.

Por qué pensar la creatividad hoy, en nuestro país. Quizás la respuesta está tan cercana a nuestra cotidianeidad que hasta resulta obvia. No hace mucho los titulares de los diarios hablaban de crisis en todos los ámbitos. En el aula, en el consultorio, en la charla de café, en la calle. El tema predominante era la crisis, la incertidumbre del mañana, la sensación de que no hay un camino o un método por excelencia que nos asegure, que existe cierto vacío, en las leyes, en las soluciones, que parece invadir todos los espacios (el individual, el familiar, el social). Pero hoy, apenas pasado cierto tiempo, no podemos abandonar la idea de incertidumbre, de falta de seguridad que acompaña todas nuestras actividades: el trabajo, el pensar el futuro, la familia, la pareja, etc. Junto con ella, comenzaron a formularse otros términos en el discurso popular que daban cuenta del surgimiento de cierto tipo de solidaridad: grupos vecinales, ollas populares y todo tipo de agrupamientos que otorgaban cierta calidez a la soledad del desarraigo, el temor al día siguiente, a la vez que generaban y posibilitaban nuevas estrategias que intentaban evitar la ruptura del tejido social, buscando superar la coyuntura y la reinserción en el mercado laboral.

Incertidumbre, complejidad, nuevas formas de relación, nuevas realidades laborales, sociales, familiares, culturales. Se suma que el peso de la responsabilidad frente a todos los hechos (desde los personales hasta los sociales) ha recaído en la persona, como sujeto individual (sujetado por sus propias limitaciones, necesidades y deseos que aunque lo neguemos también incluye a los otros como entramado del cual formamos parte). Para hacer frente a esta multitud de circunstancias aparece la idea de la creatividad en tanto conjunto de estrategias que permiten afrontar aquello que parece no tener salida bajo la forma de resolución tradicional. Pareciera que son necesarias nuevas formas.

¿Es la creatividad sólo aquello que permite inventar algo que es genial, que se vincula con las ciencias, las artes, pero que no se relaciona con el diario vivir? ¿Es la creatividad algo asociado a dotes innatas que implican cierto desapego con lo social y con las necesidades de todo ser humano? ¿De qué hablamos cuando decimos creatividad?

Crear deriva del latín y significa engendrar, producir, también se relaciona con la voz latina "crescere" que significa crecer. Bíblicamente está asociado a la creación como aquello que surge de la nada por obra divina.

Muchas de las definiciones de diccionario surgen de esta última idea y designan a la creación como la posibilidad de producir algo que no existe.

Algunos autores que se han dedicado a la creatividad señalan que crear también puede ser entendido como recrear. Se refieren a la combinación de manera nueva y original de materiales, ideas, símbolos, sonidos, etc., conformando productos y significados que antes no existían:

"es la actitud y aptitud para generar por un proceso creador, nuevas ideas, descubrir nuevos significados, inventar nuevos productos y o encontrar nuevas conexiones ya sea a nivel individual o social."

"Percibir, idear y expresar lo nuevo y significativo"

"Proceso que otorga a la persona, que genera un nuevo producto en un ambiente dado, su calidad de creadora".

"Es un proceso que se desarrolla en un tiempoespacio y en una relación sujeto-creador/objetocreado que no puede ser entendida según la lógica tradicional" (Churba, 1995) ${ }^{1}$

Todas estas definiciones hablan de cierta relación particular que se establece entre el sujeto y su necesidad de resolver situaciones. Esto implica la generación de novedades que permitirán resolver esas cuestiones mediante una mirada que involucre conocer y conceptuar la situación novedosamente, facilitando así las acciones para su resolución. Se incluye en ello una fuerte motivación que se suma a la dedicación y a amor al trabajo, necesarios para tolerar la espera y frustración que los enigmas generan en cada uno de nosotros.

\section{Puntos de partida}

Plantear la creación-recreación implica cuestionar cuál es el punto de partida de nuestro análisis, desde que lugar nos planteamos el conocimiento y nuestra relación con el mundo (si es que la creación se limita sólo al conocimiento en tanto resolución de problemas), con que disposición nos encontramos con él, quien es el sujeto que realiza este emprendimiento, cuales son las habilidades requeridas y cuando se ve facilitada su implementación.

Pero también es la posibilidad de pensar la creación mas allá del conocimiento, ampliando el concepto a la experiencia del vivir que todos compartimos como humanidad y que desde allí posibilita y limita el aprehender el mundo externo (y también el interno). La creatividad como aquello inherente a la humanidad, que se constituye en un aspecto vital y esencial como parte de la misma existencia.

La creatividad es un tema que hoy resulta conocido: hay cursos, seminarios, notas en los diarios y libros específicos. La mayoría de los textos sobre el tema enuncian un serie de pasos y movimientos (aspecto que sería plenamente contradictorio con las características del pensamiento creativo) que, básicamente, implican la posibilidad de desestructurar el pensamiento generando fluidez, flexibilidad, apertura a múltiples estímulos, etc.

Como señaláramosal iniciar esta exposición, la mayor parte de los autores, abordan la creatividad como un problema a resolver desde el orden cognitivo, olvidando al tiempo histórico-social y al sujeto que la implementa y le da lugar. Estos constituyen elementos altamente significativos para su comprensión e implementación.

Por ello, nos proponemos en las siguientes líneas desarrollar estos aspectos: pensar la creatividad como aquello que nos suscita reflexiones en un momento 
determinado, por la época que nos toca vivir y por su relación con el sujeto en su rol de actor social.

\section{El interior de la creatividad}

Nuestras experiencias cercanas en lo cotidiano y las diferentes vicisitudes del saber científico en general nos plantean que estamos arribando a una época signada por la caída de las verdades eternas, que nos encontramos con la presencia de una verdad que podríamos llamar parcial, no por incompleta sino porque se encuentra limitada por la ubicación que tiene el sujeto en el mundo. Si estamos planteando cierta relatividad en la concepción del mundo, la sensación de vacío es muy fuerte. Fuimos educados a pensar de determinada manera, buscando las certezas y sosteniendo las invariantes en pos de la verdad eterna.

Herencia cartesiana, nuestra escolaridad nos enseñó a separar, por materias, por áreas, por bolillas, por unidades. Aprendimos a aislar los objetos, a desmenuzarlos. Aprendimos a concebir la realidad como algo ajeno a nosotros como observadores. Aprendimos a explicar el todo por la constitución de sus partes. Si el todo no es el todo, si las partes no alcanzan para explicarlo, si las teorías que construimos y nos aseguraban la verdad inalterable se están desvaneciendo, la sensación de pérdida y desconsuelo es grande.

¿Cómo nos movemos en el mundo hoy? ¿Cómo no podemos explicar todo? ¿Porqué suceden estas cosas? ¿Qué nos está pasando? ¿No hay una sola realidad? Las preguntas podrían ser infinitas, sin embargo creemos que hay varios aspectos que valen la pena pensar, cuestionar, criticar y evaluar.

Nos proponemos pensar la creatividad, como proceso, que en su propio devenir intenta generar una posibilidad que no se limite a duplicar lo existente sino que conserve y estimule la posibilidad para instituir oportunidades que impliquen a aperturas a lo nuevo, a lo distinto, a lo diferente.

Creatividad en tanto concepto amplio, se puede relacionar, como decíamos en las definiciones previas con aquello que alude al origen: se remite a aspectos propios de la humanidad que crean y recrean los primeros tiempos de la existencia (considerando desde los primeros instantes del bebé hasta los primeros esbozos de la humanidad).

W innicott (W innicott, 1971) se refiere a la creatividad como" una coloración de toda la actitud hacia la realidad exterior" 2.

La creatividad queda definida en un campo intermedio que implica cierto tipo de vinculación entre ese sujeto y todo lo que lo rodea. Sabemos que el hombre desde que existe ha tratado de vincularse con todo aquello que estaba fuera y dentro de él. La creatividad tiene que ver con esa forma de relacionarnos con el mundo, que además pareciera adquirir cierto sesgo vinculado a la vitalidad.

Según este autor esta relación puede presentarse de dos maneras: una tratando de encajar en lo existente, suscitando la adaptación bajo la forma del acatamiento que en su forma extrema deriva en individuos con sentimientos de inutilidad, de estar atrapados en las redes de algún sistema, forma, sujeto, institución llevando en casos patológicos a sentimientos vinculados a la falta de deseos de vivir (¿pero quien no se ha sentido alguna vez perdido, aturdido, desenfocado, abatido, falto de ideas, falto de recursos?).

La otra forma se vincula con el sentimiento de que la vida es algo que vale la pena, que es algo que nos estimula, que representa diferentes maneras de articular y satisfacer nuestros deseos, impulsos, necesidades e instintos. El sujeto, se convierte así en el artífice de su creación/recreación en cada acto que lo conecta con el mundo.

El mismo autor señala, que entre las dos modalidades, el contraste es importante y además varía en cuanto la forma en que la realidad es entendida y el grado de objetividad que pueda tener variando de cultura y de sujeto.

\section{El acto creativo de vivir}

Es útil separar la creación como producto (ya sea una obra de arte, un texto, una comida, un instrumento, etc), donde las habilidades y la formación juegan un papel diferenciador, de la creación como idea mas amplia y anterior al producto mismo como creación. La idea misma implica una conexión con aspectos que tienen que ver con la humanidad en general, con el hecho de estar vivos y de sentirnos pertenecientes a una comunidad universal (la humanidad).

"Si se da por supuesta una capacidad cerebral razonable, una inteligencia suficiente para permitir al individuo convertirse en una persona que vive y participa en la vida de la comunidad, todo lo que se produce es creativo, salvo en la medida en que el individuo está enfermo o se encuentra frenado por factores ambientales en desarrollo que ahogan sus proceso creadores". (Winnicott, 1971) ${ }^{3}$

El ser humano fue desarrollando un aparato psíquico capaz de percibir, recordar, desear, proyectar fantasías, pensar y postergar la acción. En este juego constructivo y creativo se va relacionando, decidiendo y/o postergando. La interacción con el mundo que lo rodea irá delineando su transformación, a la vez que modifica el entorno en el cual se desarrolla. El ser humano es entonces un creador-recreador, por su propia naturaleza y ello se irá manifestando en los diversos actos de su vida, sorteando obstáculos, posibilidades, alternativas, desafiando límites, superando miedos. Tomando esta idea puede pensarse que la creatividad no es algo que pueda destruirse, sí que pueda esconderse, en circunstancias vinculadas a momentos de máximo acatamiento (campos de concentración, regímenes fundamentalistas, etc.), llevando a la constitución de una falsa personalidad que no hace mas que ocultar y proteger a modo de secreto aquello que es original, satisfactorio y creador (y vital) para ese ser humano. Recuerdo haber visto historias, poemas, dibujos, dibujados, tallados, impresos en los mas variados materiales provenientes de campos de concentración.

Pueden destruirse las obras pero no las ideas que le dieron origen, pueden destruirse objetos pero no el recuerdo y el placer asociados a ellos. De hecho, 
nosotros mismos nos vamos modificando con el tiempo, nuestras células cambian constantemente y somos los mismos y otros todo el tiempo, implementando en forma constante nuevas maneras de conectarnos con la realidad que incluyen nuevos desafíos y nuevas estrategias.

El impulso creador, entonces, puede ser pensado como algo en sí mismo. Este está presente en toda actividad, contemplación, acción (tanto en un bebé como hasta un anciano) en que se juega algo de lo que el sujeto desea, poniendo en el mismo plano las creaciones mas elaboradas y complejas como aquellas mas sencillas y esenciales (y nos referimos aquí tanto a las grandes obras como también a las pequeñas y cotidianas como cuando un niño se lleva por primera vez la cuchara a su boca como a la persona que goza con la posibilidad de su propia respiración, como al artista frente a su obra terminada).

\section{El contexto social}

La creación, considerada como impulso nos permite sostener que se encuentra en todos los seres humanos, pero ello no alcanza para explicar su desarrollo. Se hace necesario incluir una variable fundamental que es esencial y facilitadora para nuestro crecimiento: el ambiente, en tanto posibilitador o inhibidor de su despliegue.

Pensar en el ambiente implica pensar en los otros, como representantes de una comunidad (en tanto humanidad) y en tanto representantes de una cultura (como modo de praxis en el mundo, de explicación e historización). También, pensar en el ambiente incluye indagar sobre cuales son los aspectos que los sujetos poseen. 0 sea, dada las posibilidades de creatividad, cuales son las herramientas y habilidades necesarias para que un sujeto pueda utilizarlas y desplegar sus impulsos creativos.

(Winnicott, 1971) destaca la importancia que tiene la cultura en tanto posibilitadora de las acciones humanas. Enfatiza los aspectos heredados (que incluyen los aprendidos): "Pienso en algo que está contenido en el acervo común de la humanidad, a lo cual pueden contribuir los individuos y los grupos de personas, y que todos podemos usar si tenemos algún lugar en que poner lo que encontremos." 4 Desde otro plano, Edgar Morin también señala la íntima relación con la cultura en tanto praxis generadora y organizadora del capital humano. Considerada una organización recursiva se encuentra en una relación de generación e interacción mutua con la sociedad, pues son los individuos que la forman portadores y transmisores de la cultura y son sus interacciones las que regeneran la sociedad que a su vez regenera la cultura.

"Una cultura abre y cierra las potencialidades bioantropológicas del conocimiento. Las abre y las actualiza, al proveer a los individuos su saber acumulado, su lenguaje, sus paradigmas, su lógica, sus esquemas, sus métodos de aprendizaje, de investigación, de verificación, etcétera, pero al mismo tiempo las cierra e inhibe con sus normas, reglas, prohibiciones, tabúes, su etnocentrismo, su autosacralización, su ignorancia de su ignorancia. Aquí también lo que abre el conocimiento es lo que lo cierra". (Morin, 19915)

Ambos autores apelan a la tradición y a lo heredado como base para la creación. Sostienen que es la aceptación del juego que existe entre las instancias tradicionales y las instancias nuevas y originales que se posibilita el campo para la inventiva y la creación. Pensamos que no es sólo la aceptación de la existencia de estas instancias lo que posibilita la creación, sino también, la disposición del sujeto a jugar, a aceptar que es un juego y que, como tal, se encuentra en un punto intermedio entre la una y la otra.

Según Morin (Morin, 1991) : “Desde el nacimiento, el ser humano conoce por sí, para sí, en función de sí, pero también por su familia, por su tribu, por su cultura, por su sociedad, para ellas, en función de ellas" 6 .

Señala que si bien el sujeto se nutre de las experiencias culturales, a la que denomina "hipercomplejidad sociocultural" también posee su propia hipercomplejidad. "Es decir que no sólo el menor conocimiento implica componentes biológicos, cerebrales, culturales, sociales, históricos. Es decir sobre todo que la idea más simple necesita conjuntamente una formidable complejidad bío-antropológica y una hipercomplejidad sociocultural. Decir complejidad es decir - lo hemos visto- relación a la vez complementaria, concurrente, antagónica, recursiva y hologramática entre esas instancias cogeneradoras del conocimiento." 7

Al plantear esta complejidad podemos pensar en la posible autonomía relativa que cada sujeto puede alcanzar si se plantea jugar con la dependencia que significa pivotear entre sus determinantes biológicas, sus determinantes subjetivas y las determinantes culturales. Este jugar es posible justamente porque hay juego: desfasajes, cortes, silencios, aperturas. Es posible porque algo del sujeto se actualiza, porque algo del sujeto busca cambiar y aprovecha la fisura para implementar y desplegar sus experiencias creativas.

"Asi pues la posibilidad de autonomía de la mente individual está inscripta en el principio de su conocimiento, de sus ideas, de su creencias, y tanto en el nivel de su conocimiento ordinario cotidiano como en el nivel del pensamiento filosófico o científico". 8

Winnicott señala que la ubicación de la experiencia cultural es el espacio potencial que existe entre el individuo y el ambiente. Este es un espacio muy variable que tendrá que ver con sus primeras experiencias y que se diferencia de la realidad psíquica y del mundo real en tanto constantes que dependen la una de elementos biológicos-familiares y la otra de la propiedad común de la humanidad.

Para este autor, el espacio potencial de la experiencia cultural se relaciona con el espacio que existe entre el bebé y su mamá, entre el niño y su familia, entre el individuo y la sociedad/mundo, depende de la experiencia que conduce a confiar, que es considerada sagrada en el sentido que allí experimenta el vivir creador. 
Es en la confianza basada en la experiencia, ubicada"en el momento de máxima dependencia, antes del goce y empleo de la separación y la independencia" 9 .

Es a partir de sentir que se forma parte de una totalidad (la humanidad, el nosotros) que se construye la subjetividad como posibilidad de autonomía y diferencia. La subjetividad comienza cuando hay separación, cuando hay diferencia, resultado de cierto desequilibrio necesario para dar lugar a la creación. Podemos pensar que humanamente la creatividad es posible primero si existimos (vivimos), que este vivir implica el pasaje por ciertas experiencias (que incluyen lo cultural, aún en lo primordial), que permitirán constituir lo que denominamos la potencialidad creativa.

Esta potencialidad se pondrá en juego frente a la realidad (tanto externa como interna) cada vez que se transite por momentos de equilibrio / desequilibrio que representan la posibilidad de actualizar, modificar, generar, construir nuevos planos que permitan sentir plenamente el deseo de estar vivo.

En este sentido, la creatividad es general a toda la humanidad desde que nace hasta que muere y se constituye en un continuo flujo que a veces es más abundante y otras más escaso pero que como coloración nos constituye al igual que la sangre, los órganos o las moléculas.

\section{Pensando en el tiempo actual}

Niels Bohr y los partidarios de la Escuela de Copenhague pensaban que lo que conocemos no es el mundo en sí, sino el mundo con nuestro conocimiento. Que no se puede separar el mundo conocido de las estructuras del conocimiento. El mundo no existe más allá de nuestras posibilidades para entenderlo.

En este sentido, Morin (Morin, 1994) diferencia dos tipos de pensamientos: el pensamiento simple, que cree alcanzar lo verdadero, que piensa que el conocimiento es reflejo, que no considera necesario conocerse a sí para conocer al objeto y el pensamiento complejo, que necesita la vuelta auto-observable y autocrítica del observador conceptor sobre sí mismo. Hoy se habla del pasaje de la solidez de la modernidad, a la liquidez de los tiempos actuales, de la certidumbre a la incertidumbre, de la búsqueda de lo simple a la presencia de la complejidad, de la disyunción a la complementariedad.

Podría señalarse, que la modernidad fue un esfuerzo intelectual que buscaba desarrollar "la ciencia objetiva, la moral y las leyes universales" (Eagleton 1998) que implicó la creación de un vocabulario y de un cuerpo teórico para designar esa nueva realidad (nueva forma de verla) operando a la vez como guía para las transformaciones.

Pensar en la modernidad implica pararse sobre un escenario de profundas discusiones filosóficas y religiosas convulsionado por descubrimientos, el surgimiento de un nuevo orden económico y político, la imprenta, las crisis religiosas y la posibilidad de pensar desde la perspectiva del saber con nuevos criterios distanciados del marco religioso. Comienza a gestarse un proyecto que pone sobre los hombres la posibilidad de crear y recrear no solo el mundo, sino también, su explicación, como fruto de la actividad humana.

Las revoluciones e ideas de la modernidad buscaban: "... que todo eso no debía llevarse a cabo para acabar con los sólidos definitivamente ni para liberar al nuevo mundo de ellos para siempre, sino para hacer espacio a nuevos y mejores sólidos, para reemplazar el conjunto heredado de sólidos defectuosos y deficientes por otro, mejor o incluso perfecto, y por eso mismo inalterable." (Bauman, 200010)

\section{Todo estaba dicho}

La creación parecía no perseguir algo nuevo, sino, recrear en nuevos términos algo ya conocido. Busca recrear bajo la repetición de fórmulas aquello que por falta de racionalidad y apego a la superstición empañaba la felicidad de los hombres.

Por ello los primeros sólidos que debían disolverse eran las pautas sagradas, las lealtades tradicionales los derechos y obligaciones que atan de pies y manos que obstaculizaban el movimiento y limitaban la iniciativa, pero representaban también, nuevas ataduras: al determinismo de las estructuras, de la objetividad científica, del mañana mejor.

El mundo queda transformado: su medida es el hombre y sus capacidades. El costo: el relegar las percepciones al campo de lo ilusorio. La ciencia pasa de un estado contemplativo a una ciencia en actividad. La ciencia busca: transformar lo natural, conocer su interior, ubicar las causas de los fenómenos.

El mundo, tomando como ejemplo las ciencias físicas, era un mundo perfecto, que emanaba de la perfección divina: el mundo era una máquina mecánica perfecta, ordenada. Las ideas que conformaban el paradigma clásico de la modernidad partían de la concepción de un mundo físico compuesto por átomos impenetrables, que estaban allí para ser descubierto y conquistado. Es bueno aquí imaginarse estar ante un reloj y querer saber como funciona. Habrá que abrirlo e investigar sus partes, luego habrá que armarlo para ver como funciona.

Esto no es más que el método analítico que proponía Descartes: separar al to do en cada una de sus partes hasta llegar a las mas simples (aquellas que sean los últimos elementos). Así el todo que es oscuro y confuso, al ser descompuesto, permitía arribar a las partes claras y distintas. Este paradigma acentúa lo fijo y estable. La naturaleza, lo dado, se constituye en una realidad en sí misma, y está allí para ser conquistada y explicada a través de las leyes universales. El reloj, ejemplo anteriormente dado, se constituye en un modelo depurado del mecanicismo que implica el pasaje de lo intangible, como es el tiempo y la espacialidad, a un conjunto de engranajes y mecanismos invariantes y previsibles.

Este aspecto se constituye en, quizás, una de las primeras dificultades que tenemos que enfrentar cada vez que nos ponemos a pensar en algo que representa cierto desafío: hasta ahora aprendimos a pensar separando, nuestras herramientas son la reducción y la disyunción, necesitamos encontrar lo claro y 
distinto. De esta manera eliminamos el problema de la complejidad. La complejidad, es un caos porque no podemos distinguir sus partes, porque la multitud genera confusión, porque sus formas pueden ser cambiantes y porque sus posibilidades también pueden ser infinitas.

En cuantos ejemplos, modernos, lo múltiple, lo multitudinario debe ser ordenado, controlado de alguna manera. La disciplina, como muy bien señaló Foucault, (Foucault,1975) es una técnica que permite el control de las multitudes, un arte que busca la formación de un vínculo con el cuerpo humano que en el mismo mecanismo lo hace mas obediente y más útil.

La disciplina es la "anatomía política del detalle". La disciplina es un procedimiento técnico unitario por el cual la fuerza del cuerpo es reducida con el mínimo gasto como fuerza política y maximizado como fuerza útil. Nace el individuo, pero no para manifestar su autonomía, su subjetividad, sino como fuerza que debe ser neutralizada y utilizada. La masa debía ser convertida en una homogeneidad, transformada en una multiplicidad ordenada a través de procesos de selección, separación y exclusión.

El determinismo y la rigurosidad del método aseguraban que aquello que era explicado no era fruto de la imaginación sino que era producto del esfuerzo y espíritu creativo. La creación humana permitía resolver situaciones a través de la explicación analítica. Pero, también podría sostenerse, que en el mismo acto la explicación no era más que recreación, en tanto repetición de aquello que estaba ahí para ser descubierto.

La ciencia exploraba el campo de lo que podía ser determinado y dejaba la intrusión de lo casual para los poetas y los filósofos. La creatividad estaba atada a pasos fijos que, por supuesto, dieron sus frutos. Pero la ciencia rechazaba to do aquello que desafiaba las bases sólidas que aseguraban la construcción del pensamiento.

(Prigogine, 1994) sostiene que: "La idea de las leyes de la naturaleza tiene una connotación legalista: parecería que la naturaleza está "obligada" a seguir ciertas leyes [... ] La idea de que el mundo estaría sujeto a las leyes apareció en forma gradual en el pensamiento de Occidente. Muchos historiadores piensan que en esto desempeñó un papel esencial el Dios cristiano concebido como legislador omnipotente. A Dios todo le es dado. La novedad, la elección o la acción espontánea dependen de nuestro punto de vista humano. El descubrimiento de las leyes inmodificables de la naturaleza habría aproximado entonces el conocimiento humano a un punto de vista divino, atemporal." 11

Como señala Schnitman (Schnitman, 1994): “Este programa tuvo un éxito inmenso. La explicación de cualquier fenómeno natural en términos de leyes deterministas parecía al alcance de la mano, y una vez que contáramos con esas leyes básicas, de ello se derivaría todo lo demás (la vida, nuestra conciencia humana) por simple deducción." 12

Pero el determinismo invadió todos los campos, especialmente el marco social de lo cotidiano. Los vínculos sociales, e incluso los familiares, eran pensados como estables, sólidos e indisolubles. Las aspiraciones vinculadas a la constitución de parejas y al amor se caracterizaban por lo que se ha dado en llamar el "amor romántico" (Giddens, 1992). Este amor se sostenía en la creencia de que se podía establecer un lazo duradero con otro sobre la base de cualidades propias de ese vínculo (" para siempre", "el único", "el verdadero"). El siglo XX fue testigo del pasaje de estas formas de vinculación romántica a un nuevo modelo denominado "amor confluente" . Estas nuevas formas ponen su acento en la relación, y ya no sólo en la persona, y se basan en la idea de dar y recibir emocionalmente en forma igualitaria. Incluyen, también, expresar preocupaciones y necesidades por el otro de la pareja. E incorporan, como parte del "contrato romántico", el placer sexual recíproco.

En el campo laboral: el trabajo, la oficina, la fábrica implicaban rutinas de formación y capacitación, rutinas de desempeño simbolizados por la vocación al trabajo, como la misión en torno a la cual giraba la vida. La fábrica, la oficina, la empresa se constituían en escenarios donde el sujeto entraba al iniciarse en el área laboral y de donde finalmente se retiraba cuando terminaba su período productivo.

La máquina social-económico-política estaba aceitada y su funcionamiento parecía adecuado para el logro de las metas estimadas. La creatividad quedaba, como en el trabajo, asociada al proceso productivo. La ciencia y la tecnología prestaron importantes aportes. Pero también, la creatividad quedaba atada a los límites de la producción y al servicio de solución de los problemas, pero no asociado a la posibilidad de asumir una posición crítica que pudiera implicar un paso fuera de lo planeado.

Los teóricos del trabajo sintetizaron las ideas de esas épocas bajo la denominación de programa. El programa tenía metas y pasos preestablecidos. La creatividad se encontraba limitada a las diferentes habilidades para cumplimentar lo esperado en el tiempo mínimo y con la mayor eficacia. El problema se presentaba cuando algo, no contemplado aparecía. El programa carecía de respuestas para responder a la demanda. El nuevo paradigma arrojó una nueva luz sobre la cuestión y acuñó la noción de estrategia. La misma es concebida como un escenario donde la acción puede modificarse en función de las informaciones y acontecimientos. Ya no hay sólo pasos fijos, sino además, preparación para trabajar con la incertidumbre, a partir una concepción holís-tica que incluye la elaboración y transformación de la tarea como así también de sus objetivos.

Otro aspecto importante a considerar fue la aspiración a arribar a conocimientos verdaderos. Para ello nace una nueva metodología científica que tras el abandono de la autoridad académica externa y los textos sagrados "magister aix", propone un criterio basado en la experiencia personal.

Esta experiencia personal es lo que llamamos evidencia. El sujeto se encontraba en condiciones de examinar por sus propios medios las pruebas a favor o en contra de aquello que quería conocer. Esta nueva 
manera de considerar la validez de los conocimientos colocaba en el hombre la posibilidad y las dotes para lograrlo.

La condición entonces fue que el sujeto se separara del objeto y que el objeto fuera separado de su entorno. Sin embargo, su comprensión dio origen a dos grandes maneras de entender a la experiencia personal: por un lado debía ser entendida como evidencias intelectuales, fruto de la libre reflexión racional y por el otro lado fue interpretada como evidencias sensoriales, única base para fundar el conocimiento.

Aquí nuevamente, podemos observar la operación de la disyunción, que a través de largos debates ocupó a la filosofía y también a otras ciencias.

\section{Historia sin fin}

Es en el seno de las consideradas ciencias, duras y sólidas, que comienza a disolverse el determinismo y la incertidumbre con el fluir del siglo XX. Hay coincidencia entre los diferentes autores acerca de las situaciones que hacen nuestra modernidad diferente y novedosa.

La primera es el gradual colapso y decadencia de la ilusión, que el camino que transitamos tiene un final, un estado de perfección que podrá ser alcanzado en un futuro mejor: la sociedad buena, justa y sin conflictos.

Este ideal dependía de cierta concepción de la humanidad como entidad universal cuya realización progresiva implicaba su conceptualización como proceso unitario, alrededor del cual se reunían y ordenaban todos los acontecimientos. La idea de la historia como proceso unitario cae y junto con ella la idea del progreso.

Si no hay un solo camino para el desarrollo de los acontecimientos, poco se podrá sostener que se avanza hacia un fin y que ese fin a su vez implicará la emancipación del hombre proyectado como realización de la civilización.

Como señala Bauman (Bauman, 2001) citando a Benjamín: “... la historia no es ni una línea recta ni un proceso acumulativo, como querría hacernos creer la afamada "versión progresista" de la historia. Siendo la repulsión, no la atracción, la principal fuerza motriz de la historia, el cambio histórico se produce porque los humanos se ven mortificados e irritados por lo que perciben como doloroso y desagradable en su condición, porque no desean que persistan ese condiciones y porque buscan el modo de mitigar o remediar su sufrimiento." 13

En este camino, muchos autores consideran el papel desempeñado por los medios masivos de comunicación, que aún con la debatida globalización, posibilitan mostrar la diversidad de puntos de vista y realidades locales. Este caos informático, en función de la misma lógica del mercado, exige una ampliación continua del mismo, y en consecuencia habilita cada vez más elementos como objetos de la comunicación. En este sentido, "la transparencia", como diría Vattimo (Vattimo, 1990), estaría al servicio de mostrar a modo de espejo la condición humana en todas sus posibilidades de expresión. Esta multiplicidad, de- vuelve un complejo entramado de imágenes, que compiten entre sí, generando caos y posibilitando la emancipación.

Otro de los conceptos es el referido a la configuración de nuevas relaciones entre las ciencias. El contexto actual ha catalizado la formación de nuevas ciencias y nuevas tecnologías que ya no se constituyen como formaciones aisladas e independientes sino, justamente, como componentes de nuevas configuraciones, donde las relaciones y los intercambios son constantes. Muchos de los pensadores provienen de diversas ciencias (física, química, biología, etc.) e incluso, sus trabajos también trascienden las fronteras clásicas de la división de campos generando aportes que van de una ciencia a otra.

Una de las características de esta nueva configuración es la inclusión del desorden en su papel constructivo. Junto con esta noción aparece la posibilidad de la autoorganización como una nueva posibilidad vinculada a un nuevo estado diferente e impensado en el paradigma anterior. El sujeto, el tiempo y la historicidad ya no son eliminados sino que, justamente, tienen una participación sustantiva en la construcción del conocimiento (a diferencia de la ciencia clásica donde el sujeto era eliminado como condición de objetividad).

Ya no hablamos de la historia sino de las historias, ya no hablamos de un tiempo sino del recorte temporal, que además varía según el sujeto, que a su vez está determinado por múltiples variantes que adquieren diversas configuraciones de acuerdo al recorte cognitivo que realicemos.

Todo conocimiento arroja un cono de luz y un cono de sombra. Nos marca sus alcances e ilumina el lugar donde realizará su profundización. Pero también nos marcará sus límites y sus sombras (aquello que desconocemos, que no consideramos por la misma relatividad que el conocimiento impone)

Como señala Prigogine (Prigogine, 1994): “El tiempo y la realidad están ligados irreductiblemente. Negar el tiempo puede ser un consuelo o parecer un triunfo de la razón humana, pero es siempre una negación de la realidad". Citando a Borges agrega: "Negar la sucesión temporal, negar el yo, negar el universo astronómico, son desesperaciones aparentes y consuelos secretos. Nuestro destino (...) no es espantoso por irreal: es espantoso porque es irreversible y de hierro..." 14

En la ciencia clásica, el cosmos era el orden y se oponía al caos que significaba desorden. Orden (y podemos dar gracias a Aristóteles) era lo que podía ser clasificado, analizado, incorporado dentro del discurso racional.

El siglo XX ha aportado en esta línea nuevas conceptualizaciones: el caos puede conducir al orden, nuevos estados de la materia emergen en estados alejados del equilibrio. Por otro lado el cosmos, universo mecánico y eterno, se desplomó con el descubrimiento de la dispersión de las galaxias y la hipótesis de que el mundo nace de una explosión original. "Explosión" hace referencia a algo con mucho calor y el calor en la física significa agitación, desordenada partículas de átomos. En este desorden se producen 
ciertas asociaciones, cierto principio de orden, que permiten constituir ciertas formaciones que luego dan lugar a las galaxias y los astros.

Por lo tanto, el desorden existe y además desempeña un papel productor en el universo. Si el desorden tiene un papel productor en el universo, también lo tendrá en cada uno de las partículas del mismo y en cada una de las formaciones que se desarrollen como resultado de esa nueva configuración.

Podemos pensar esto en relación a las organizaciones sociales: desde las formales del estado pasando por las sindicales, vecinales, escolares, etc. Como señalábamos al principio de este trabajo, la(s) historia(s) reciente(s) (y también no tan recientes) de nuestro país nos muestran que en relación a las organizaciones populares, estas se han transformado, algunas han desaparecido y nuevas han aparecido, conviviendo a la vez con formas más convencionales.

Muchos científicos, (como el ya nombrado Prygogine) sostienen que el universo tiene capacidad de renovarse permanentemente. El desorden no interfiere en los procesos de auto-organización, sino que los estimula, el desorden tiene un papel constructivo en la creación de un nuevo orden.

"El mundo, tal como lo ve la caótica, es rico en evoluciones impredectibles, lleno de formas complejas y flujos turbulentos, caracterizado por relaciones no lineales entre causas y efectos, y fracturado entre escalas múltiples de diferente magnitud que vuelven precaria la globalización. Las nubes, las cataratas, son metáforas turbulentas, impredictibles, irregulares e infinitamente variables. Pequeñas fluctuaciones se amplifican en cambios de gran escala." (Schintamn, 199415)

\section{Interacción en el sistema}

Lo que propone el pensamiento complejo es no olvidar que la realidad es cambiante, que lo nuevo puede surgir y que de todas maneras va a surgir. Lo primero que enseña la complejidad es que nada está aislado y todo está en relación. 0 sea, no solo que hay relación sino que, la parte está en el todo y que el todo está en cada una de las partes. Pensemos en los efectos familiares de una crisis, los cambios y rupturas que una pérdida laboral puede ocasionar. También, y ampliando la mirada: la clonación y sus debates, o la globalización que nos muestra buenos ejemplos: el efecto tequila en la economía, la caída de las torres gemelas y sus repercusiones políticas en todo el mundo, etc.

Este modo de pensar implica una concepción holística, de creciente interdependencia (ej: asociaciones, MERCOSUR, OTAN, etc), de superación de las dicotomías (ej: sujeto-sociedad; sujeto-objeto), y mayor pluralismo. En este punto el desafío es interesante, la superación de las dicotomías implica aceptar la idea de la complementariedad, algo puede ser de una manera en un contexto y de otra en otro. Pero ello no invalida ni justifica ninguna de las dos concepciones como únicas y además nos muestra que estamos condenados, por nuestra propia limitación humana, a sólo observar una por vez.
La ciencia busca reintegrar al hombre con la naturaleza que estudia, a responsabilizarse por sus desarrollos y comienza a abandonar la ambición de llevar de nuevo el conjunto de procesos a un pequeño número de leyes. Ejemplo: en el mundo del pensamiento es el surgimiento de nuevas ciencias como la ecología, cuyo concepto central es el de ecosistema, sosteniendo la interacción entre diferentes organismos y sistemas; e indicando cierto movimiento de reconciliación con el entorno terrestre.

Esta capacidad de renovación a partir del desorden nos habilita a reconceptualizar la creatividad y su relación con el vacío (como sentimiento, quizás como temor). Si la realidad no es natural sino construida, también puede ser interrogada, cuestionada y recons-truida. El desorden no es algo que está fuera sino que debería ser incluído, no en su relación de opuesto sino, justamente, como complemento.

También se puede agregar que, desde el punto de vista de la misma creatividad, y partiendo de la noción de ecosistema, son las personas, como grupo, familia, institución, empresa o nación, las que deberían desarrollar y desplegar el potencial creador de sus integrantes, estimulando, en forma grupal, la apertura a lo nuevo.

\section{Libertad versus seguridad}

Otro de los elementos a considerar (y que afecta en forma más clara el plano de la cotidianeidad) tiene que ver con la idea de libertad y su relación con la seguridad.

Liberarse es deshacerse de las ataduras que impiden o limitan el movimiento. El siglo XX mostró que el mundo es reticente a someterse a nuestra voluntad, es restrictivo, limitante y desobediente. El siglo XX mostró los horrores, que en nombre de la libertad y de la seguridad, el hombre es capaz de realizar. Sentirse libre de restricciones, libre de actuar, es alcanzar cierto equilibrio entre los deseos y la imaginación y la capacidad de actuar. Sentirse libre implica la capacidad de poder evaluar y también tener la capacidad, o sea, las herramientas y habilidades necesarias para poder crear en libertad.

¿Cómo sentirnos libres y poder actuar en un mundo que cada vez nos deja más solos y resulta mas temible y poco contenedor?

Como señala Bauman (Bauman, 2000): “ No podemos ser humanos sin seguridad y libertad, pero no podemos tener ambas a la vez, y ambas en cantidades que consideremos plenamente satisfactorias" 16 .

Promover la seguridad implica perder parte de nuestra libertad y viceversa. Pero la seguridad sin libertad equivale a esclavitud y la libertad sin seguridad se relaciona con cierto sentimiento de pérdida y abandono. La libertad desde la modernidad es un bien preciado, pero la seguridad es también una necesidad que es inherente al hombre.

Estas nociones se relacionan, también, con la idea de otros como sociedad, como cultura compartida. La pertenencia misma implica diferencia: otros y nootros (los distintos, los diferentes). Quizás deberíamos preguntarnos de qué hablamos cuando decimos libertad y qué queremos significar cuando hablamos 
de seguridad. Ambos conceptos invaden, en forma permanente, el discurso social y político, generando diferencias e intentando imposiciones.

¿Cuántas guerras se realizaron (realizan) en nombre de la libertad?

¿Cuántas para proteger la seguridad?

En este sentido el vacío creativo también puede ser pensado como aquello frente a lo cual nos vemos arrojados pero que, quizás, todavía no todos estamos en condiciones de enfrentar. Nuestras experiencias creativas infantiles no encuentran un espacio para desplegar su potencialidad. Aparece así, la noción de soledad, que pareciera referir al individuo que se encuentra teniendo que enfrentarse a la inermidad de la vida.

La comunidad protectora se muestra desarmada. Los cambios y la velocidad de los mismos no hacen más que acentuar cotidianamente la interacción con múltiples situaciones donde los intercambios son breves y superficiales, donde a pesar de interactuar en un día con más sujetos de los imaginados, estos han perdido la categoría de vínculo. Son tantos y tan inestables: el cartero no es siempre el mismo, las vendedoras en un supermercado (aunque algunos almacenes sobreviven) tienden a cambiar, al igual que el colectivero y con los vecinos no hay mas que un buen día, ¿qué tal? que no busca respuesta sino el sólo saludar.

Es importante remarcar que el sentimiento entonces podría generarse por la distancia entre lo deseado como ideal (cómo deben ser los vínculos en una sociedad, en la ciudad, en el barrio) y como se dan en forma concreta (interacciones superficiales y breves que delinean un forma particular en la constitución de los lazos).

¿Será por temor al compromiso?

¿Será para no ser dañado?

¿Será por el acento puesto en los derechos antes que en el deber?

Parte de este sentimiento podría relacionarse con la idea de Bauman (2000) acerca de las responsabilidades sociales. Este autor sostiene que el peso de las tareas y responsabilidades que antes detentaba la sociedad ha recaído, en la modernidad líquida, sobre los individuos. Las tareas han sido fragmentadas e individualizadas. La idea del progreso en tanto accionar de la sociedad en su conjunto ha sido abandonada y el énfasis ha sido volcado en la autoafirmación del individuo.

Se ha producido en términos axiológicos un corrimiento en cuanto a los deberes y los derechos: el deber de construir una sociedad justa que emancipara a sus miembros se ha transformado en una sociedad de los derechos humanos, donde cada uno tiene el derecho de elegir y tomar los caminos para alcanzar la propia felicidad.

La modernidad original era pesada en la cima y la actual es liviana luego de liberarse de sus deberes emancipadores salvo, el de delegar el trabajo de la emancipación en las capas medias y bajas sobre las que ha recaído la mayor parte de la carga de la continua modernización. Ya no hay líderes que digan que hacer, liberando al sujeto de la responsabilidad de sus actos, en el mundo de los individuos solo hay otros individuos de quienes se puede tomar el ejemplo de cómo moverse en los asuntos de su vida, cargando con toda la responsabilidad de haber confiado en ese ejemplo y no en otro.

Se dice no hay líderes, no hay modelos. Lo que no hay es un líder o un modelo que funcione en forma paradigmática. Las decisiones y las responsabilidades son individuales. El sujeto se siente sólo y aislado. Pero si nos paramos en la complejidad las dificultades que la misma complejidad genera son propias del desafío del pensamiento e implican aperturas para posibilitar cambios creativos. El tema es si estamos preparados.

Pensar en la complejidad es pensar incluyendo la incertidumbre, pero no desde un escepticismo resignado sino, justamente, aceptando esta complejidad como parte de la aventura humana. Pero también, en la línea de lo expuesto, es aceptar la cuota de responsabilidad que a cada uno le corresponde. En este sentido, ni la ciencia ni los científicos se encuentran hoy en condiciones de sustraerse a los efectos y resultados de aquello que investigan.

Podemos pensar creativamente en términos del nuevo paradigma, o solo lo podemos enunciar pero nos cuesta implementarlo. Pensemos en nuestros vínculos por ejemplo la familia: hoy hay muchas definiciones que aluden a la variedad de su conformación: monoparentales, ensambladas, tradicional, etc. Un niño medio tiene varios conjuntos de hermanos, de abuelos, etc. Ningún vínculo (ni lo primarios) tienen garantía de estabilidad ni seguridad.

Pero internamente ¿seguimos pensando en la familia tradicional burguesa?

¿Qué pasa entre el ideal y su realidad?

¿Será la caída de los ideales aprendidos como valiosos y dignos de ser buscados los que nos genera ese vacío existencial?

¿Será el vacío la posibilidad de gestar nuevos ideales a sabiendas que la incertidumbre y la falta de garantías serán marcas en su desarrollo?

¿Cómo pensar la creatividad en términos vinculados a la complejidad?

¿Por qué pensar la creatividad hoy? ¿Qué es nuestra vida, qué hacemos cotidianamente?

\section{En el final (y al principio), la creación}

Tras un breve ejercicio de reflexión podríamos decir que prácticamente casi todas nuestras actividades y casi todos nuestros pensamientos funcionan de manera automática. No sólo porque muchas de las actividades complejas se han simplificado, no sólo porque la era digital con apretar un botón nos permiten conectarnos con el otro lado del planeta sino, porque pareciera que nos deslizamos por la realidad en forma suave y sin obstáculos. Metáfora de ello son las grandes construcciones de este siglo (grandes centros comerciales, aeropuertos, hipermercados, autopistas etc) donde predominan los metales, los vidrios, las cintas de desplazamiento, dando también paso a la existencia, como señala Marc Augé (Augé, 1992) de los denominados "no lugares", aquellos espacios especialmente diseñados 
para la rápida circulación de bienes y personas. Podemos manejar, hablar por teléfono, navegar por internet y masticar un chicle sin entrar en crisis. Nuestra vida humana podríamos decir que se ha desconectado tanto de nuestra conciencia que casi (en honor a Descartes) se ha convertido en una máquina perdiendo sus cualidades humanas y adquiriendo las características de un mundo donde los objetos y la inteligencia artificial gobiernan.

Pero parece que nos tienen que pasar cosas para que nos liberemos de los grandes relatos. Parece que las promesas de felicidad y de progreso no solo se agotaron en el siglo XX sino que en nuestra propia cotidianeidad pudimos comprobar que las promesas de los grandes políticos, que las promesas del consumo, que la seducción de los objetos quizás nos dio cierta identidad, quizás nos dio cierto éxitos pero poco de felicidad, poco de creatividad, poco de humanidad y mucho de diferencia y exclusión.

Quizás podríamos preguntarnos por qué el éxito de estas promesas, por qué el éxito de estos determinismos. Como señala Bauman (Bauman, 2001) parte de la cuestión podría estar asociada a la seguridad que estas ideas, que estos objetos nos otorgan, Pero como consideráramos anteriormente esta seguridad pareciera que se encuentra en relación inversa con nuestra libertad y ella tiene íntima relación con nuestra creatividad.

Las crisis alientan nuestra creatividad, nos sacan del entumecimiento, del automatismo, nos alientan a aventurarnos al mundo (al igual que los que realizaron tantos descubrimientos) corriendo los riesgos que los mismos implican, sabiendo que no hay certezas pero aceptando el desafío que toda empresa, emprendimiento o simplemente encuentro con lo nuevo implica.

La vida adquiere entonces cierta tonalidad asociada con la pasión, que como una luz ilumina una posibilidad en aquello que era dado como instituido. Pero en ese movimiento aparece cierta sensación de vacío.

Ese vacío incluye, entre otros, dos aspectos: uno asociado a lo cognitivo, falta de grandes teorías, caída y limitación de su validez y por otro lado cierto vacío asociado a la soledad que estos cuestionamientos a veces parecen transmitir.

¿Es un vacío que representa una ausencia, allí donde algo debiera estar?

¿Es un vacío que representa una pérdida de aquello que estuvo y ahora no está?

¿Es un vacío porque representa algo diferente y no sabemos o nos animamos a sacudir nuestros automatismos y generar nuevos campos?

Quizás es la posibilidad de realizar un nuevo salto. Quizás es la apertura a nuevos desafíos y la posibilidad para nuevas formas de emancipación.

"En la medida en que las predicciones deterministas no son posibles, es probable que las visiones del futuro, y hasta las utopías, desempeñen un papel importante en esta construcción. Hay personas que le temen a las utopías; yo le temo más a la falta de utopías. ¿Estaremos asistiendo a un momento de transición de la humanidad hacia una nueva etapa en que un mayor número de personas participen en la cultura y puedan manifestar su creatividad? (Prigogine, 1994) $^{17}$

Prigogine nos plantea en el final de su cita la participación cultural. Es posible advertir que el vacío se encuentra también a nivel cultural. Estamos llenos de objetos, llenos de mensajes, pero vacíos de respuestas, mudos e impotentes frente a lo distinto y a lo que nos afrenta. Pareciera existir cierto divorcio entre las experiencias y las necesidades individuales y la capacidad de integración simbólica que sólo el ámbito de lo cultural puede ofrecer. Los valores, las costumbres, los avances tecnológicos, el empobrecimiento económico, la desvalorización de la función educativa o la precarización de ella para algunos sectores y la intensa estimulación de los medios masivos de comunicación se constituyen, entre otros, en factores que producen cambios en el ámbito de lo social y que por lo tanto requieren de respuestas. El resultado de ello podría ser entendido como una carencia de sentido (por lo menos de sentidos no únicos) que dificulta la vida en comunidad, justamente por su ausencia. La falta y debilitamiento de las respuestas culturales que permitirían a los sujetos guiar sus posibles elecciones y acciones, los deja también solos y desvalidos frente a acontecimientos que siempre resultaron esenciales a la vida humana: la muerte, la enfermedad, el desvalimiento, el desempleo, etc.

Las diferencias entonces entre los distintos sectores son grandes y se deslizan fácilmente hacia la exclusión.

La cultura implica, como señalábamos al iniciar esta reflexión, una relación de generación mutua con la sociedad. Cultura es comunidad de sentidos, es organización recursiva organizada y organizadora del capital cognitivo colectivo, de las habilidades aprendidas, de las experiencias compartidas, de la memoria histórica y de las creencias míticas.

Las características referidas sobre la época actual diseminan sobre el entramado social, aquello que debiera unirlo, incitando a la búsqueda individual de respuestas que produce a su vez mayor distanciamiento de los elementos que generan la sensación de comunidad. Proliferan los llamados a las soluciones personales que paradójicamente no pueden cubrir las carencias de lo simbólico en tanto producción social y dejan una sensación de abandono y soledad difícil de tolerar.

El sujeto se encuentra solo porque hay debilitamiento de los lazos comunitarios, porque hay debilitamiento desde lo simbólico y porque hay refuerzo de lo individual. Como decía Auge, esta una época signada por los excesos: exceso de generaciones que conviven en un mismo tiempo y lugar, exceso de tiempos y distancias y fundamentalmente exceso de individuo. Terminando por donde empezamos crear / recrear puede tener distintos sentidos de acuerdo a la forma en que encaramos la vida. Si creamos-recreamos en función de nuestros deseos, cuestionando, construyendo, reconstruyendo nos acercamos a una postura asociada a la experiencia creativa original en todo sujeto. 
Si recreamos-creamos como repetición, en el sentido de sumisión, de automatización, nos inclinamos por una postura más deshumanizada, más automática, más repetitiva y por ello poco creativa.

Abordar la creación y transitar sus caminos es un desafío que exige correr riesgos, abrir el mundo propio y abrirse al mundo externo, animarse a explorar, a comunicar lo nuevo y lo original, a trabajar mucho, resistir frustraciones y a soltar la pasión.

Quizás, sea este un aspecto interesante para pensar acerca de la creatividad como una cualidad propia de la humanidad, que puede ser desarrollada y ejercitada transformando nuestro sobrevivir en una base saludable para nuestro vivir.

\section{Notas}

${ }^{1}$ Churba, C. (1995) La Creatividad. (Pág. 8). Buenos Aires: Dunken.

2 Winnicott, D (1971): Realidad y Juego (Pág. 93) Barcelona: Gedisa

${ }^{3}$ Winnicott, D. Op. Cit. (Pág. 96)

${ }^{4}$ Winnicott, D. Op. Cit. (Pág. 133)

${ }^{5}$ Morin, E. (1991): Cultura n Conocimiento ( Pág. 75) en Watzlawick :El Ojo del Observador. Barcelona: Gedisa, 1994

${ }^{6}$ Ibídem, Pág. 75

7 Ibídem. Pág. 77

${ }^{8}$ Ibídem. Pág. 78

${ }^{9}$ Winnicott, D. Op. Cit. Pág. 137

${ }^{10}$ Bauman, Z. (2000): M odernidad Líquida. (Pág 9)Buenos Aires: Fondo de Cultura Económica, 2003.

${ }^{11}$ Prigogine, I. (1994): ¿El fin de la ciencia? (Pág. 38) en Nuevos Paradigmas, Cultura y Subjetividad. Buenos Aires: Paidos, 2003.

12 Schnitman, D. (1994): Nuevos Paradigmas, Cultura y Subjetividad. (Pág 38). Buenos Aires: Paidos, 2003.

${ }_{13}$ Bauman, Z. (2001): Comunidad (Pág. 26). Buenos Aires: Siglo Veintiuno, 2003.

${ }^{14}$ Prigogine, I. (1994): De los Relojes a las Nubes (Pág. 409) en Schnitman D. Op. Cit.

${ }^{15}$ Schnitman, D. Op. Cit. Pág. 21.

${ }^{16}$ Bauman, .Comunidad, Pág 12.

17 Prigogine, De los relojes..., Pág. 412.

\section{Bibliografía}

Augé, M. (1992): Los “no lugares”. Barcelona: Gedisa, 1994.

Bauman, Z. (2001): Comunidad. Buenos Aires: Siglo Veintiuno, 2003.

Bauman, Z. (2000): Modernidad Líquida. Buenos Aires:

Fondo de Cultura Económica, 2003.

Churba, C. (1995): La Creatividad. Buenos Aires:

Dunken, 1995.

Díaz, E. (1999): Posmodernidad. Buenos Aires: Biblos, 1999.

Eagleton, T. (1998): Las ilusiones del posmodernismo.

Buenos Aires: Paidos, 1998.

Foucault, M. (1975. Vigilar y castigar. M éxico: Siglo

Veintiuno, 1995.

Freud, S. (1907), El Creador literario y el fantaseo. OCT

IX. Buenos Aires:Amorrortu. 1993.

Giddens, A. (1992). La transformación de la intimidad.

Madrid: Cátedra, 1995.

Guerrero, A. (1988). Curso de Creatividad. Buenos

Aires: El Ateneo,1992.

Jameson, F. (1991. Ensayos sobre el posmodernismo. Buenos Aires: Imago Mundi,1991.
Le Breton, D. (1990). Antropología del cuerpo y modernidad. Buenos Aires: Nueva Visión,1995. Lipovetsky, G. (1983). La era del vacío. Barcelona: Anagrama, 1996.

Morin, E. (1991). Cultura y Conocimiento. En el Ojo del Observador. Barcelona: Gedisa, 1994.

Schnitman, Nuevos paradigmas, cultura y subjetividad. Buenos Aires: Paidos, 1994.

Prigogine, I. (1994). De los relojes a las nubes. En Schnitman, Nuevos paradigmas, cultura y subjetividad. Buenos Aires: Paidos, 1994.

Prigogine, I. (1994). ¿El fin de la ciencia? En Schnitman, Nuevos Paradigmas, cultura y subjetividad. Buenos Aires: Paidos, 1994.

Roa, A. (1995):.M odernidad y Posmodernidad. Chile: Andrés Bello, 1995.

Romo, M. (1997). Psicología de la creatividad. Barcelona: Paidos Ibérica, 1997.

Sarlo, B. (2001). Tiempo presente. Buenos Aires: Siglo Veintiuno, 2001.

Scnitman, D. (1994). Nuevos Paradigmas, Cultura y Subjetividad. Buenos Aires: Paidos. 2002

Vattimo G. y otros (1990). En torno a la posmodernidad. Barcelona: Anthropos, 1994. Watzlawick P. y Krieg P., comps (1991). El Ojo del observador. Barcelona: Gedisa, 1994.

Winnicott, D (1971). Realidad y Juego. Barcelona: Gedisa, 2000. 